\title{
Circulating biomarkers in malignant pleural mesothelioma
}

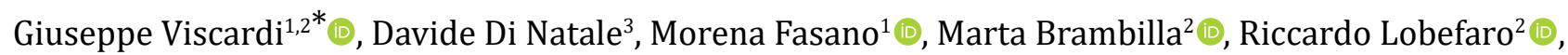 \\ Alessandro De Toma² ${ }^{\oplus}$, Giulia Galli² ${ }^{\circledR}$ \\ ${ }^{1}$ Department of Precision Medicine, Università degli Studi della Campania “Luigi Vanvitelli”, 80131 Naples, Italy \\ ${ }^{2}$ Department of Medical Oncology, Fondazione IRCCS Istituto Nazionale Tumori, 20133 Milan, Italy \\ ${ }^{3}$ Department of Translational Medical Sciences, Università degli Studi della Campania "Luigi Vanvitelli", 80131 Naples, Italy
}

*Correspondence: Giuseppe Viscardi, Department of Precision Medicine, Università degli Studi della Campania "Luigi Vanvitelli”, Via Sergio Pansini 5, 80131 Naples, Italy; Department of Medical Oncology, Fondazione IRCCS Istituto Nazionale Tumori, Via Giacomo Venezian 1, 20133 Milan, Italy. giuseppe.viscardi@hotmail.it

Academic Editor: Graham Packham, University of Southampton, UK

Received: May 21, 2020 Accepted: December 9, 2020 Published: December 28, 2020

Cite this article: Viscardi G, Di Natale D, Fasano M, Brambilla M, Lobefaro R, De Toma A, et al. Circulating biomarkers in malignant pleural mesothelioma. Explor Target Antitumor Ther. 2020;1:434-51. https://doi.org/10.37349/etat.2020.00028

\begin{abstract}
Malignant pleural mesothelioma (MPM) is an aggressive tumor strictly connected to asbestos exposure. Prognosis is dismal as diagnosis commonly occurs in advanced stage. Radiological screenings have not proven to be effective and also pathological diagnosis may be challenging. In the era of precision oncology, validation of robust non-invasive biomarkers for screening of asbestos-exposed individuals, assessment of prognosis and prediction of response to treatments remains an important unmet clinical need. This review provides an overview on current understanding and possible applications of liquid biopsy in MPM, mostly focused on the utility as diagnostic and prognostic test.
\end{abstract}

\section{Keywords}

Mesothelioma, malignant pleural mesothelioma, liquid biopsy, biomarkers, mesothelin, miRNAs, CTC, ctDNA

\section{Introduction}

Malignant pleural mesothelioma (MPM) is a tumor strictly connected with occupational and/or environmental exposure to asbestos [1]. Epithelioid subtype occurs more frequently (60\%), whereas approximately $10 \%$ of MPMs are sarcomatoid and the remainder biphasic. Prognosis remains dismal as it commonly diagnosed in advanced stage and response to available medical treatments is poor. Moreover, paradigm shift of precision medicine has not yet translated into new systemic approaches [2].

Regarding mechanisms of tumorigenesis, chronic inflammation has been linked to the initiation and progression of MPM. Inhalation of asbestos fibers results in a response characterized by recruitment of macrophages and neutrophils, production of pro-inflammatory cytokines, cell proliferation and angiogenesis [3]. As result, MPM is characterized by a low mutational burden and a genomic landscape dominated by inactivation of several tumor suppressors genes, such as cyclin-dependent kinase inhibitor $2 \mathrm{~A}$ (CDKN2A), BRCA1 associated protein (BAP1) and neurofibromatosis 2 (NF2) [4].

(C) The Author(s) 2020. This is an Open Access article licensed under a Creative Commons Attribution 4.0 International License (https://creativecommons.org/licenses/by/4.0/), which permits unrestricted use, sharing, adaptation, distribution and reproduction in any medium or format, for any purpose, even commercially, as long as you give appropriate credit to the original author(s) and the source, provide a link to the Creative Commons license, and indicate if changes were made. 
So far, radiological screenings have not proven to be effective for detecting early MPM among asbestos-exposed subjects [5]. Also differential diagnosis of MPM is sometimes very difficult. A wide tissue immunohistochemical staining, including mesothelioma-associated markers as Wilms tumor-1 (WT-1), calretinin, cytokeratin5/6 (CK5/6) and podoplanin is required for diagnosis and differentiation from pulmonary carcinoma or metastasis from other tumors [6, 7]. Since sarcomatoid histotype often does not express these markers and most commonly only stains for pan-Cytokeratin, GATA binding protein 3 (GATA-3) has been proposed as sensitive and specific biomarker for distinguishing sarcomatoid mesothelioma from sarcomatoid carcinoma of the lung [8]. Finally, BAP1 immunostaining and CDKN2A/p16 fluorescence insitu hybridization (FISH) in effusion cytology specimens are useful in distinguishing malignant from benign mesothelial proliferation, although BAP1 and p16 are not deleted or lost in all MPM tumors [9]. In particular, $B A P 1$ is the most commonly mutated gene in MPM and loss of nuclear staining occurs in more than $60 \%$ of tumors [10], while homozygous deletion of $C D K N 2 A$ is seen in 70\% of epithelial MPM [11,12].

In this scenario, use of biological fluids, such as blood and pleural effusion, represents an ideal source of non-invasive biomarkers. Tumor cells can release into bloodstream different molecules (proteins and nucleic acids, also epigenetically modulated); circulating tumor cells (CTCs) and extracellular vesicles (EV) can be detected too (Figure 1).

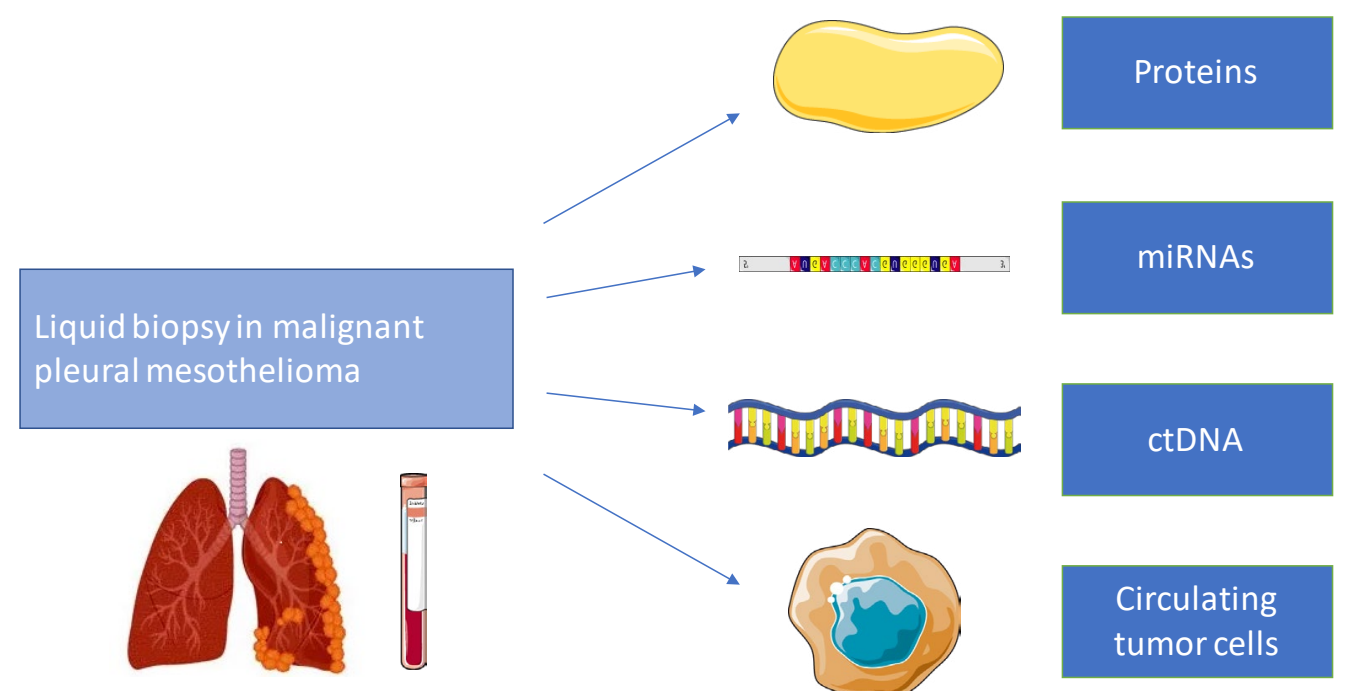

Figure 1. Circulating biomarkers analysis in malignant pleural mesothelioma

So, the search for biomarkers, useful for early detection, prognosis and in the prediction of response to treatments appears as a promising field of investigation [13]. This review provides an overview on current understanding and possible developments of liquid biopsy in MPM, mostly focused on its utility as diagnostic and prognostic test.

\section{Proteins}

A number of proteins have been evaluated in MPM over this time as diagnostic or screening markers. At the moment, mesothelin remains the most extensively studied and the only blood-based test approved by Food and Drug Administration (FDA) for detecting MPM recurrence in patients following surgery or assess response to therapies. Further candidate protein biomarkers include osteopontin (OPN), fibulin-3 (FBLN3), high-mobility group box 1 (HMGB1) protein, angiogenic factors, syndecan-1 (CD138), whereas proteomics represents a promising new approach (Table 1).

\section{Mesothelin}

Mesothelin is a cell surface glycoprotein expressed in several tumors type, including MPM (limited to epithelioid subtype), ovarian and pancreatic adenocarcinoma, whereas normal tissues, unless mesothelial cells, exhibit very low or no expression. In particular, the term SMRP designs three isoforms, known as variant 1,2 and 3 , that can be shed by tumor cells into bloodstream [14]. 
Table 1. Overview on proteins as biomarkers in liquid biopsy for MPM

\begin{tabular}{|c|c|c|c|c|}
\hline Author & Biomarker & Study design & Samples & Role \\
\hline $\begin{array}{l}\text { Robinson et al. } \\
2013 \text { [16] }\end{array}$ & SMRP & $\begin{array}{l}\text { MPM }=44 ; \mathrm{HS}=68(40 \mathrm{AES}) \\
\mathrm{OPD}=160\end{array}$ & Serum & $\begin{array}{l}\text { Diagnosis: MPM vs. OPD } \\
\text { (sensitivity } 84 \% \text {, specificity } 100 \% \text { ) }\end{array}$ \\
\hline $\begin{array}{l}\text { Creaney et al. } \\
2011[24]\end{array}$ & SMRP & MPM = 97 & Serum & Prognosis; response to treatment \\
\hline $\begin{array}{l}\text { Wheatley-Price et al. } \\
2010 \text { [25] }\end{array}$ & SMRP & $\mathrm{MPM}=41$ & Plasma & Response to treatment \\
\hline $\begin{array}{l}\text { Pass et al. } \\
2005[34]\end{array}$ & OPN & $\mathrm{MPM}=76 ; \mathrm{AES}=69$ & Serum & $\begin{array}{l}\text { Diagnosis: MPM vs. AES } \\
\text { (sensitivity } 77.6 \% \text {, specificity } 85.5 \% \text { ) }\end{array}$ \\
\hline $\begin{array}{l}\text { Cristaudo et al. } \\
2011 \text { [39] }\end{array}$ & SMRP + OPN & MPM $=31 ; B R D=204$ & Serum; plasma & $\begin{array}{l}\text { Diagnosis: MPM vs. BRD } \\
\text { (sensitivity } 80 \% \text {, specificity } 91.2 \% \text { ) }\end{array}$ \\
\hline \multirow[t]{2}{*}{$\begin{array}{l}\text { Pass et al. } \\
2012 \text { [42] }\end{array}$} & FBLN3 & $\begin{array}{l}M P M=92 ; A E S=136 \\
O P E=93 ; H S=43\end{array}$ & Plasma & $\begin{array}{l}\text { Diagnosis: MPM vs. AES } \\
\text { (sensitivity } 100 \% \text {, specificity } 94.1 \% \text { ) }\end{array}$ \\
\hline & & $\mathrm{MPM}=74 ; \mathrm{OPE}=93$ & Pleural effusion & $\begin{array}{l}\text { Diagnosis: MPM vs. OPE } \\
\text { (sensitivity } 83.8 \% \text {, specificity } 92.4 \% \text { ) }\end{array}$ \\
\hline $\begin{array}{l}\text { Creaney et al. } \\
2014 \text { [43] }\end{array}$ & FBLN3 & $\mathrm{MPM}=82 ; \mathrm{OPE}=71$ & Pleural effusion & $\begin{array}{l}\text { Diagnosis: MPM vs. OPE } \\
\text { (sensitivity } 22 \% \text {, specificity } 95 \% \text { ); } \\
\text { prognosis }\end{array}$ \\
\hline $\begin{array}{l}\text { Tabata et al. } \\
2013 \text { [47] }\end{array}$ & HMGB1 & $\mathrm{MPM}=61 ; \mathrm{AES}=45$ & Serum & $\begin{array}{l}\text { Diagnosis: MPM vs. AES } \\
\text { (sensitivity } 34.4 \% \text {, specificity 100\%); } \\
\text { prognosis }\end{array}$ \\
\hline $\begin{array}{l}\text { Hirayama et al. } \\
2011 \text { [52] }\end{array}$ & VEGF & $\mathrm{MPM}=46 ; \mathrm{OPE}=45$ & Pleural effusion & $\begin{array}{l}\text { Diagnosis: MPM vs. OPE } \\
\text { (sensitivity } 71.7 \% \text {, specificity } 76 \% \text { ); } \\
\text { prognosis }\end{array}$ \\
\hline $\begin{array}{l}\text { Mundt et al. } \\
2014 \text { [59] }\end{array}$ & CD138 & MPM = 89; OPE = 167 & Pleural effusion & $\begin{array}{l}\text { Diagnosis: MPM vs. OPE } \\
\text { (sensitivity } 74.9 \% \text {, specificity } 61.3 \% \text { ); } \\
\text { prognosis }\end{array}$ \\
\hline
\end{tabular}

SMRP: soluble mesothelin related peptide; VEGF: vascular endothelial growth factor; AES: asbestos exposed subject; BRD: benign respiratory diseases; OPD: other pleural diseases; OPE: other pleural effusions

Many studies attempted to assess SMRP levels in patients with MPM compared to those with nonmalignant pleural disease, lung cancer and subjects exposed to asbestos, or in other cases in patients with MPM before and after treatment.

Notably, SMRP is currently the only FDA approved MPM biomarker, being Mesomark, an enzyme-linked immunosorbent assay (ELISA)-based assay, the available kit most studied for measurement of this protein in blood and pleural effusion. The cut-offs used to define an abnormal result ranged from $0.5 \mathrm{nmol} / \mathrm{L}$ to $3.3 \mathrm{nmol} / \mathrm{L}$. Described limit of detection is $0.16 \mathrm{nmol} / \mathrm{L}$ and intra-assay imprecision (CV) $1.1-5.3 \%$, whereas serum bilirubin, hemoglobin, triglycerides or chemotherapeutic agents do not interfere with measurement [15].

In a key study published in 2003 by Robinson et al. [16], elevated serum levels of SMRP, correlating with tumor size too, were detected in $84 \%$ of patients with MPM $(n=44), 2 \%$ of subjects with other cancers of inflammatory lung or pleural conditions $(n=120)$ and none of 28 controls never exposed to asbestos.

Subsequently, other heterogeneous investigations hypothesized that serum SMRP was a possible marker for diagnosis. However, a metanalysis of 16 studies showed that, employing a cut-off of $2.00 \mathrm{nmol} / \mathrm{L}$, sensitivity ranged from $19 \%$ to $68 \%$ and specificity from $88 \%$ to $100 \%$ [17]. Despite the good specificity, other factors such as age, chronic kidney failure or obesity may be responsible of SMRP alteration [18]. Clearly, poor sensitivity limits the accuracy as diagnostic biomarker, moreover in early- stage disease and sarcomatoid mesothelioma. A cluster of MPM characterized by high score of epithelial mesenchymal transition (EMT) and poor prognosis, also shows low expression of mesothelin as consequence of promoter methylation, as previously reported for sarcomatoid type [19].

Radiologic assessment of disease and response to treatments is another issue commonly presenting in clinical management of MPM. Response evaluation criteria in solid tumors (RECIST) criteria appear 
inadequate, as one-dimensional measures of a tumor with a non-spherical pattern of growth are difficult [20]. Some findings support the potential value of changes in mesothelin levels for monitoring of treatment response.

High baseline SMRP levels were independently associated with poor prognosis in three prospective studies encompassing respectively 107, 96 and 100 MPM patients [21-23]. Creaney et al. [24], longitudinally assessed mesothelin serum concentrations from 97 patients diagnosed with MPM. At baseline mesothelin levels strongly correlated with tumor burden and metabolically active tumor volume as measured by fluorodeoxyglucose-positron emission tomography (FDG-PET), rather than with TNM stage. Despite the few patients examined, mesothelin levels always declined after cytoreductive surgery. Also, in patients receiving chemotherapy, there was a significant association between radiological response and decrease of serum mesothelin, as well as between change in mesothelin levels on therapy and overall survival (OS). A significant association between response outcome and relative change in plasmatic levels in 21 patients receiving systemic therapy for MPM was confirmed by Wheatley-Price et al. [25], for mesothelin, but not for OPN. However, small sample size, heterogeneity in choice of cut-off value and therapeutic interventions make difficult to draw conclusions about prognostic role of SMRP.

Lastly, given high levels of expression in MPM and limited expression in normal tissues, mesothelin represents an interesting target for development of new therapies [26]. As multiple agents are under investigation, including monoclonal antibody, antibody-drug conjugate, adoptive $\mathrm{T}$ cell therapy and vaccines, noninvasive biomarkers for predicting and assessing response are critical for their translation in clinical practice. As mesothelin immunohistochemistry is not predictive of response to targeted therapies, different biomarkers are to explore.

The role of megakaryocyte potentiating factor (MPF) has been investigated for this purpose. It is known that the mesothelin gene encodes a precursor protein that is cleaved into membrane-bound mesothelin and soluble MPF, whose serum level reflects the expression of target antigen mesothelin on tumor cells. For detection MPF assay uses a capture antibody MPF49 and a detection antibody MPF25, while mesothelintargeted agents do not react with MPF [27]. Analyzing serum samples collected from patients enrolled in two clinical trials with anti-mesothelin immunotoxin SS1P [28, 29], Cao et al. [30], described, in presence of elevated baseline values, reduction of MPF in patients who reached partial response (PR) during systemic therapies and its association with better progression free survival (PFS) and OS. However, due to small number of patients and retrospective nature of analysis, this exploratory evidence needs to be validated prospectively in largest studies.

\section{OPN}

OPN is an extracellular matrix protein that interacts with several surface receptors and is involved in biological processes (as bone remodeling, immune modulation and apoptosis) and pathologies (comprising infections, autoimmune disease and cancer). Several tissues and, at increased levels, tumor cells from multiple tumor types express OPN [31-33].

In the first report by Pass et al. [34], OPN serum level was associated with duration of asbestos exposure and radiographic abnormalities, showing good ability to differentiate asymptomatic asbestos-exposed individuals and early-stage mesothelioma patients (sensitivity of $84.6 \%$ and specificity of $88.4 \%$ at a cutoff value of $62.4 \mathrm{ng} / \mathrm{mL}$ ). Unlike mesothelin it has been proven to rise also in patients with sarcomatoid MPM [34]. Of note, this first study did not include patients with other pleural malignancies and nonmalignant asbestos-induced pleural diseases as controls. In another investigation led by Grigoriu et al. [22], serum OPN showed insufficient specificity as diagnostic marker, being unable to discriminate between MPM and pleural metastases or benign pleural lesions caused by asbestos exposure.

In a metanalysis encompassing six studies, OPN demonstrated only a mild diagnostic sensitivity $(0.65$, 95\% CI: 0.60-0.70) and moderate specificity (0.81, 95\% CI: 0.78-0.85), being AUC under ROC curve 0.83 [35]. In this analysis serum and plasma exhibited comparable diagnostic accuracy, although OPN levels in plasma are generally higher, because of the lower stability of serum OPN caused by thrombin cleavage during the coagulation cascade [36]. As previously reported, other pre-analytical factors (as storage conditions and 
number of thawing) may affect OPN stability. Moreover, the choice of the ELISA kit highly influences the result of dosage [37].

Regarding evaluation of response to treatments, it has been reported that OPN levels increase together with radiological response, unlike mesothelin and MPF. This may reflect the effects of tissue remodeling on OPN levels. However, higher baseline OPN levels remained associated with shorter survival [38].

Based on the ability of serum mesothelin to diagnose epithelioid MPM and of OPN to distinguish between patients with MPM and healthy asbestos-exposed subjects, Cristaudo et al. [39], proposed to combine SMRP and plasmatic OPN in a "combined risk index" to increase both sensitivity and specificity as diagnostic marker.

\section{FBLN3}

FBLN3 is a member of fibulin family of secreted glycoproteins and contains calcium-binding sites. It forms part of extracellular matrix and is broadly expressed on basement membranes of epithelial and endothelial cells. FBLN3 is directly involved in tissue remodeling, as well as in cell growth and tumor angiogenesis [40]. In tumorigenesis FBLN3 may have varying tissue-dependent roles [41].

Pass et al. [42], firstly reported data from 92 MPM patients and 290 controls. They reported elevated levels of FBLN3 both in plasma and pleural effusion capable to separate, with sensitivity and specificity exceeding that of any previously investigated marker, MPM patients from healthy subjects and from those with effusion due to other causes.

In spite of these results subsequent investigations have provided conflicting results. After studying a cohort of 192 patients, Creaney et al. [43], reported a sensitivity of $22 \%$ and a specificity of $95 \%$ for plasma FBLN3, although they hypothesized a superior prognostic value of FBLN3 compared with mesothelin. Data from Kirschner et al. [44], confirmed the potential prognostic value of pleural fluid FBLN3, but questioned the diagnostic role of this marker in MPM patients.

\section{HMGB1}

HMGB1 is a member of the high-mobility group protein super-family, physiologically expressed in the nucleus of cells. Its binding to Toll like receptors (TLRs) and receptor for advanced glycation end products (RAGE) mediates the response to infectious agents and tissue injury, resulting in the promotion of inflammation and cell proliferation [45]. A key role as modulator in MPM development has also been reported. Asbestos inhalation induces mesothelial cell necrosis with release of HMGB1 in the extra-cellular space and secretion of TNF- $\alpha$ from inflammatory cells. Therefore, activation of NF-kB pathway contributes to transformation of mesothelial cells [46].

Tabata et al. [47], demonstrated that patients with MPM $(n=61)$ had significantly higher serum levels of HMGB1, as measured using an ELISA kit, than healthy individuals exposed to asbestos $(n=45)$. Despite a low sensitivity (34.4\%), they reported very promising specificity and positive predictive value (PPV) for MPM diagnosis $(100 \%$ for both at cut-off value of $9.0 \mathrm{ng} / \mathrm{mL})$. Moreover, in this study baseline stage and serum HMGB1 levels performed as independent prognostic factors, suggesting its utility as prognostic as well as diagnostic marker.

Results from Napolitano et al. [48], suggested a role for hyperacetylated HMGB1 as diagnostic marker. Specifically, at a threshold of $2.0 \mathrm{ng} / \mathrm{mL}$ they reported sensitivity and specificity of $100 \%$ in discriminating patients with MPM compared to individuals exposed to asbestos and healthy controls. They quantified HMGB1 isoform in vitro, through mass spectrometry (MS) techniques, in supernatants from MPM and mesothelial cells, and found a prevalence of hyperacetylated protein in MPM. These findings are consistent with a passive release of nonacetylated HMGB1 from nucleus of necrotic cells after asbestos-induced necrosis, and active secretion of hyperacetylated isoform from cytoplasm of transformed cells.

\section{Angiogenic factors}

VEGF is recognized as a critical regulator of vascular permeability, endothelial cell proliferation and angiogenesis. VEGF expression is well documented in MPM too, acting as autocrine growth factor and mitogen for mesothelial cells $[49,50]$. 
As serum VEGF levels are reported to be affected by clotting through its release from platelets, a critical issue is the choice of optimal specimen for its measurement. VEGF levels in plasma are low and close to limits of ELISA sensitivity. Since platelets reservoir of VEGF may have a role in neoangiogenesis and metastasis formation, dosing VEGF from serum may improve the clinical value as biomarker [51].

Using an ELISA kit, Hirayama et al. [52], reported that patients with MPM $(n=46)$ had significantly higher pleural effusion VEGF levels than those with non-malignant pleuritis $(n=25)$ or malignant pleural effusion from lung cancer ( $n=20$, sensitivity $71.7 \%$ and specificity $76.0 \%$, cut-off $2,000 \mathrm{pg} / \mathrm{mL}$ ). Following 28 patients with MPM, they described a significant correlation between pleural effusion VEGF levels and survival. Furthermore, serum and pleural effusion levels among 16 MPM patients were significantly closely correlate. Likewise, Yasumitsu et al. [53], reported a significant correlation between high serum VEGF concentration and worse survival (cut-off at $460 \mathrm{pg} / \mathrm{mL}$ ), and the usefulness of serum VEGF to differentiate MPM patients $(n=51)$ and those with asbestosis or pleural plaques $(n=29)$. Despite Fiorelli et al. [54], observed no significant differences between malignant effusions from lung cancer $(n=11)$ and mesothelioma $(n=13)$ in VEGF levels, their data supported the use of this marker in ruling out malignancy in diagnostic work up of pleural effusion, showing that median VEGF level was significantly higher in malignant $(n=49)$ than that in benign exudates $(n=15)$.

Of interest, VEGF-targeted therapies, including bevacizumab, have been extensively investigated in MPM, but no predictive biomarkers have been identified [55]. In the MAPS trial baseline serum VEGF levels were available in 372/448 (83\%) of patients. Prognostic role was confirmed, but the interaction between treatment arms (bevacizumab containing arm vs. chemotherapy-alone) and VEGF levels was not significant for PFS and OS [56]. Similarly, none of potential explored biomarkers were predictive of response to nintedanib in the LUME-Meso trial [57].

\section{CD138}

CD138 is a cell surface glycoprotein that regulates biological processes as cell proliferation, migration and angiogenesis trough interaction with growth factor receptors and integrins. Its extracellular domain is shed into body fluids after cleavage by metalloproteinase and carries attachment sites for heparan sulfate chains [58].

In a study by Mundt et al. [59], pleural fluid, but not serum levels, distinguished between benign and malignant pleural effusion, from both metastatic carcinoma and pleural mesothelioma (sensitivity of 74.9\%, specificity of $61.3 \%$ at the cutoff of $65.7 \mathrm{ng} / \mathrm{mL}$ ). Furthermore, low levels of shed CD138 in pleural effusions predict a more favorable prognosis in patients with pleural malignancies. However, the discriminatory power of this marker seems to be insufficient to use as a sole diagnostic marker.

\section{Proteomics}

The investigation of panels of simultaneously measured biomarkers represents an alternative to ELISA assays, which allow the study of a single candidate biomarker at time. Proteomics approach, through comparison of protein expression profile between normal samples and disease affected ones, can provide detection of new biomarkers [60]. Majority of methods for proteomics analysis are based on MS [61].

Cerciello et al. [62], used selected reaction monitoring (SRM) assay technology to evaluate the surfaceomederived MPM biomarkers in serum samples of MPM subjects and controls. They identified a panel of seven glycopeptides, including mesothelin, who performs better than mesothelin alone in detecting MPM vs. nonsmall cell lung cancer (NSCLC) or pleural benign disease (sensitivity $91 \%$ vs. $74 \%$, specificity $78 \%$ vs. 74\%).

Kao et al. [63] identified secreted protein acidic and rich in cysteine (SPARC) as candidate prognostic plasmatic biomarker in a discovery series of 12 MPM patients through an isobaric tags for relative and absolute quantitation (iTRAC) analysis [64]. SPARC is expressed in both tumor cells and cancerassociated fibroblast [65]. In the extracellular matrix it can modulates the interaction between cells and microenvironment, performing a role in tumorigenesis. Its prognostic role was reported in a larger retrospective series of 97 patients, finding that median survival was higher in patients with low SPARC compared with those with high SPARC (19.0 months vs. 8.8 months, $P=0.01)$ [63]. 
The slow off-rate modified aptamers (SOMAmers) proteomic technology has been used by Ostroff et al. [66] to analyze serum from 117 MPM cases and 142 high risk control patients and screen over 1, 000 protein. So, they discovered and validated a 13-biomarker panel for detection of MPM in the asbestosexposed population (sensitivity/specificity 94\%/91\%, accuracy of 92\%). Interestingly, SOMAmer panel includes proteins that are involved in biological processes as inflammation, cell growth regulation and cellular adhesion [67-68].

\section{MicroRNAs (miRNAs)}

miRNAs are non-coding RNA, 20-25 nucleotides long, that regulate gene expression at post-transcriptional level by binding the 3 '-untranslated regions of their messenger RNA (mRNA) targets and inhibiting translation or inducing cleavage [69].

As expected, miRNAs are involved in main human diseases, ranging from cardiovascular disorders to cancer. In tumorigenesis miRNAs can act as either tumour suppressors or oncogenes, as several targets correspond to a single miRNA. Genome-wide profiling demonstrates that miRNA expression signatures are associated with tumor type and clinical outcomes. So, miRNAs could be potential candidates for diagnostic and prognostic biomarkers, or therapeutic targets tools [70].

miRNAs are secreted into the liquid fraction of peripheral blood or other body fluids inside exosomes or in vesicle-free forms, associated with high density lipoproteins (HDL) or Argonaute proteins [71]. Therefore, these molecules can be extracted and profiled.

During the discovery phase high throughput techniques, as microarray hybridization, enable the identification of a wide number of miRNAs. Quantitative techniques, as real-time reverse transcription quantitative polymerase chain reaction (RT-qPCR) or next generation sequencing (NGS) are used during the following validation phase [72]. The choice of an appropriate normalization method, able to reduce analytical variability, represents another important aspect in miRNA quantification for clinical implementation [73].

Regarding MPM patients, many studies investigated circulating miRNA profile with the aim of identifying markers for early detection, differential diagnosis and prognosis [74] (Table 2).

Table 2. Overview on miRNA as biomarkers in liquid biopsy for MPM

\begin{tabular}{|c|c|c|c|c|}
\hline Author & Biomarker & Study design & Samples & Role \\
\hline $\begin{array}{l}\text { Santarelli et al. } \\
2011 \text { [77] }\end{array}$ & miR-126 & $\begin{array}{l}M P M=44 ; A E S=196 \\
H S=55\end{array}$ & Serum & $\begin{array}{l}\text { Diagnosis: MPM vs. AES } \\
\text { (sensitivity } 73 \% \text {, specificity } 74 \% \text { ) }\end{array}$ \\
\hline $\begin{array}{l}\text { Kirschner et al. } \\
2011 \text { [84] }\end{array}$ & miR-625 & $M P M=30 ; A E S=10$ & Serum & $\begin{array}{l}\text { Diagnosis: MPM vs. AES } \\
\text { (sensitivity } 70 \% \text {, specificity } 90 \% \text { ) }\end{array}$ \\
\hline $\begin{array}{l}\text { Weber et al. } \\
2012[88]\end{array}$ & $\operatorname{miR}-103 a$ & $M P M=23 ; A E S=17$ & Blood & $\begin{array}{l}\text { Diagnosis: MPM vs. AES } \\
\text { (sensitivity } 83 \% \text {, specificity } 71 \% \text { ) }\end{array}$ \\
\hline $\begin{array}{l}\text { Weber et al. } \\
2017 \text { [81] }\end{array}$ & miR-132 & $M P M=21 ; A E S=21$ & Plasma & $\begin{array}{l}\text { Diagnosis: MPM vs. AES } \\
\text { (sensitivity } 86 \% \text {, specificity } 61 \% \text { ) }\end{array}$ \\
\hline $\begin{array}{l}\text { Cavalleri et al. } \\
2017 \text { [87] }\end{array}$ & $\begin{array}{l}\text { miR-103 + miR-30e } \\
\text { EVs }\end{array}$ & $M P M=23 ; A E S=19$ & Plasma & $\begin{array}{l}\text { Diagnosis: MPM vs. AES } \\
\text { (sensitivity } 95.5 \% \text {, specificity } 80 \% \text { ) }\end{array}$ \\
\hline
\end{tabular}

In 2009 Guled et al. [75], were among the first to compare miRNA profile in MPM cells and normal human pericardium using microarrays. They identified 12 over-expressed (let-7b, miR-30b, miR-32, miR195, miR-345, miR-483-3p, miR-584, miR-595, miR-615-3p, and miR-1228) and 9 down-regulated miRNAs (let-7e, miR-7-1, miR-9, miR-34a, miR-144, miR-203, miR-340 and miR-423, miR-582) in neoplastic cells. Among those over-expressed, miR-30b, miR-32, miR-483-3p, miR-584, and miR-885-3p regulate the tumor suppressor genes $C D K N 2 A$ and NF2, whereas downregulated miRNAs such as miR-9, miR-7-1 and miR-203 have as targets the oncogenes hepatocyte growth factor $(H G F)$, platelet derived growth factor subunit $\mathrm{A}$ (PDGFA), epidermal growth factor (EGF) and Jun oncogene (UUN). Of interest, the majority of these miRNAs are located in chromosomal regions already known as altered in MPM, such as 8q24, 1p36, and 14q32 [76]. 
As reported below, among those studied in MPM patients, more evidence emerged about the role as possible circulating biomarkers of miR-126-3p, miR-103a-3p and miR-625.

In 2011 Santarelli et al. [77] obtained a miRNA signature by analyzing biopsies collected at diagnosis from MPM patients, compared to healthy human mesothelium. Among eight significantly downregulated miRNAs, miR-126 acts as tumor suppressor by decreasing the translation of vascular endothelial growth factor-A (VEGF-A) mRNA. Evaluation of serum samples obtained from 44 MPM patients, 196 asbestosexposed and 55 HS confirmed higher concentrations of SMRP and VEGF in MPM patients. On the other hand, low levels of MiR-126 correlated with high concentration of VEGF and discriminated high risk individuals from HS (sensitivity 60\%, specificity 74\%) and MPM patients (sensitivity 73\%, specificity 74\%) [77].

In another contribution the same group demonstrated that a "3-biomarker classifier", based on serum levels of SMRP, miR-126 and methylated thrombomodulin promoter (Met-TM), improved the differential diagnosis of MPM from asbestos-exposed subjects and healthy controls, when compared to SMRP alone [78].

Under expression of miR-126 in serum was confirmed in the study of Tomasetti et al. [79], capable to discriminate MPM patients from those with NSCLC or HS, using relative qRT-PCR. Conversely, miR-126 levels did not differentiate NSCLC patients from controls. In this study, results were normalized to small nuclear RNA U6 as endogenous control and the cel-miR-39 as exogenous control. The low expression of miR-126 was also associated with a worse prognosis, corroborating the clinical meaning of this biomarker. However, dysregulation of U6 levels in different conditions limits its potential use for normalization of circulating miRNA analysis. For instance, U6 levels were significantly upregulated in sera of patients with chronic inflammatory diseases [80].

Weber et al. [81], showed different expression levels of circulating miR-132 between mesothelioma patients and asbestos-exposed controls. For discrimination, sensitivity of $86 \%$ and specificity of $61 \%$ were calculated. Combining miR-132 with the previously described miR-126, sensitivity of $77 \%$ and specificity of $86 \%$ were obtained.

More recently, Bononi et al. [82], found three miRNAs (miR-197-3p, miR-32-3p and miR-1281) to be upregulated in MPM patients compared to HS and workers ex-exposed to asbestos (WEA), and the latter also upregulated in WEA compared to HS. Instead, the down regulation of miR-126 in serum was not confirmed. In this investigation MiR-3665, an endogenous stable microRNA (MiR-3665), was also proposed as suitable normalizer. Forkhead box 03 (FOXO3), a key gene promoting apoptosis, is reported as a target of miR-197. It has also been published that miR-32-3p acts as oncogene down-regulating phosphatase and tensin homolog (PTEN) and targeted B-cell translocation gene 2 (BTG2) [83].

Kirschner et al. [84], firstly reported elevated levels of a circulating miRNA with potential value as biomarker, describing, through a microarray analysis, 15 miRNAs upregulated in MPM patients compared with controls. In fact, through qRT-PCR, they demonstrated higher levels of miR-625-3p in the serum of MPM patients ( $n=30$ ) compared to AES ( $n=10$, sensitivity 70\%, specificity 90\%). However, these data were normalized against miR-16, which is known to be altered in MPM and influenced by sample haemolysis [85]. In a study aimed to assess the effects of miR-625-3p on thyroid cancer cells it appears to promote proliferation, migration and invasion by enhancing the expression of astrocyte elevated gene-1 (AEG-1) and activating downstream Wnt/ $\beta$-catenin and Janus kinase (JNK) pathways [86]. Finally, diagnostic approaches different from those described above were proposed in other works.

In 2017 Cavalleri et al. [87], using an OpenArray method, identified a new miRNA signature in exosomes isolated from plasma. More specifically, a combination of miR-103a-3p and miR-30e-3p discriminated MPM and WEA (sensitivity $95.8 \%$, specificity $80 \%$ ).

In two consecutive works Weber et al. [88], quantified miRNAs in cellular fraction of peripheral blood. In the first study, downregulated miR-103 showed sensitivity of $83 \%$ with specificity of $71 \%$, and sensitivity of $78 \%$ with specificity of $76 \%$ for discrimination of MPM from AES and the general population, respectively. In the second investigation, to enhance the performance of this biomarker the authors suggested a combination of miR-103a-3p and mesothelin to differentiate MPM and WEA (sensitivity 95\%, specificity 81\%) [89]. 


\section{Circulating tumor DNA (ctDNA)}

Circulating free DNA (cfDNA) is released from healthy and cancerous tissues undergoing apoptosis or necrosis. ctDNA originates from tumor cells and carries somatic mutations, representing only a small fraction of cfDNA.

Notably, cfDNA demonstrates a wide potential as biomarker in oncology for multiple indications including staging and prognosis, monitoring response to treatments or minimal residual disease and identification of acquired resistance mechanisms to drugs [90].

The degree of cfDNA integrity, called integrity index, is based on the ratio between long and short cfDNA fragments and has been investigated as biomarker. Sriram et al. [91], found that pleural fluid DNA integrity index was higher in MPM $(n=52)$ than in benign effusions $(n=23)$. In particular, an high pleural fluid DNA integrity index exhibited a PPV of $81 \%$ in detecting MPM in patients with cytology-negative pleural effusion, suggesting its usefulness to guide more invasive procedures in this population (Table 3).

Table 3. Overview on various biomarkers in liquid biopsy for MPM

\begin{tabular}{|c|c|c|c|c|}
\hline Author & Biomarker & Study design & Samples & Role \\
\hline $\begin{array}{l}\text { Santarelli et al. } \\
2015 \text { [78] }\end{array}$ & Methylated TM & $\begin{array}{l}M P M=45 ; A E S=99 \\
H S=44\end{array}$ & Serum & $\begin{array}{l}\text { Diagnosis: MPM vs. controls } \\
\text { (sensitivity } 60 \% \text {, specificity } 81 \% \text { ) }\end{array}$ \\
\hline $\begin{array}{l}\text { Sriram et al. } \\
2014 \text { [91] }\end{array}$ & DNA integrity index (+ citology) & $\mathrm{MPE}=52 ; \mathrm{OPE}=23$ & $\begin{array}{l}\text { Pleural } \\
\text { effusion }\end{array}$ & $\begin{array}{l}\text { Diagnosis: MPM vs. OPE } \\
\text { (sensitivity } 81 \% \text {, specificity } 87 \% \text { ) }\end{array}$ \\
\hline $\begin{array}{l}\text { Yoneda et al. } \\
2019 \text { [97] }\end{array}$ & Podoplanin & MPM = 15 & Blood & $\begin{array}{l}\text { Diagnosis: CTC-chip vs. CellSearch } \\
\text { (sensitivity } 63.3 \%-64.5 \% \text { ); prognosis }\end{array}$ \\
\hline
\end{tabular}

TM: thrombomodulin

New perspectives have been opened afterwards the demonstration of the presence of ctDNA in treatment naïve MPM patients. Hylebos et al. [92], performed whole exome sequencing (WES) on paired germline and tumor DNA of ten MPM patients to identify cancer-specific variants of interest. Hence, using droplet digital PCR (ddPCR), they confirmed the presence of selected mutations in serum samples of three out of five treatment naive patients (detection rate $60 \%$ ) at allelic fractions ranging from 0.28 to $0.9 \%$. On the other hand, the absence of detectable tumor specific alterations in cfDNA of patients who received chemotherapy is interesting in view of the potential use of ctDNA as a biomarker for treatment response assessment.

However, broad implementation of ctDNA analysis in daily clinical practice requires validation of these data as well as use of accessible and cost-effectiveness technique.

\section{CTCs}

CTCs are cells shed by solid tumors and circulating in the bloodstream. As CTCs play a key role in development of distant metastases, they could provide useful information in a variety of malignancies. However, their identification requires highly sensitive techniques, as they are present in a very small numbers [93].

Among various systems developed, CellSearch is the only FDA-approved for clinical purpose. It detects cells expressing epithelial cell adhesion molecule (EpCAM) through magnetic particles coated with specific antibodies [94]. As important limitation, CTCs without EpCAM expression, such as those exhibiting EMT or of non-epithelial origin, may not be recognized [95]. Accordingly, CellSearch presents a low sensibility for identification of CTCs for MPM.

To overcome this issue a CTC-chip system coated with an anti-podoplanin antibody has been developed [96]. In peripheral blood drawn from 15 MPM patients, the CTC-chip showed better performance to detect CTCs in all pathological subtypes over CellSearch $(68.8 \%$ vs. 6.3\%; $P<0.001)$, and the capability to predict unresectable disease (area under the ROC curve, 0.851 ). Setting a cut-off value of 2 cells $/ \mathrm{mL}$, an higher CTC count was also significantly associated with worse prognosis, and count decrease was demonstrated after surgical resection or tumor shrinkage [97] (Table 3). 


\section{Epigenetic biomarkers}

Epigenetic modifications occurring during tumor evolution can be detected in fluids and serve as potential biomarkers [98]. In asbestos-induced carcinogenesis, reactive oxygen species (ROS) formation is responsible of gene promoter methylation, through poly(ADP-ribose) polymerase 1 (PARP1) and DNA (cytosine-5) methyltransferase 1 (DNMT1) recruitment [99]. Interestingly, epigenetic biomarkers could represent novel therapy targets.

Nocchi L et al. [100], combined two epigenetically regulated markers (miR-126 and TM) with SMPR. In fact, it has been reported that, in MPM tissue, TM gene expression can be silenced through epigenetic mechanisms and, similarly, hypermethylation of miR-126 promoter region is responsible for its downregulation [101]. Despite the poor sensitivity (60\%), the authors reported that circulating methylated TM DNA significantly discriminated MPM patients from controls with high specificity (82\%), thus complementing the performance of miR-126 and SMRP alone for MPM detection [78] (Table 3).

More recently, Guarrera et al. [102], using a genome-wide methylation array, found differential methylation patterns of selected CpGs in DNA extracted from white blood cells (WBC) between MPM patients ( $n=163$ ) and controls $(n=137)$. The most hypo-methylated single-CpG is located in a gene coding for a transcription factor, namely Forkhead-box K1 (FOXK1), which directly interacts with BAP1. Significantly, FOXK1 maps to chromosome 7p22.2, one of the genomic areas described as associated to MPM [103], whereas somatic and germline mutation of $B A P 1$ is reported in MPM $[10,104]$.

\section{Exosomes}

Exosomes are small nano-EV derived from the endosomal pathway and released from normal and cancer cells. Their presence in body fluids makes them potential novel biomarkers for early diagnosis and prognostication, as well as therapeutic targets [105].

The protein composition of in vitro produced exosomes has been studied using MS, demonstrating that exosomes derived from MPM tumour cells contain select miRNAs or cargo proteins known to be associated with angiogenesis, cell migration, metastasis, and immunoregulation [106]. Exosomes present in pleural fluid may have various cellular origins, as highlighted through proteomic analysis of malignant effusion [107].

A current limitation to adopt them as biomarkers is represented from the lack of standardization of techniques required for isolation (based on differential centrifugation) and characterization (including flow cytometry, proteomic and MS analysis).

\section{Immunophenotype of circulating cells}

A great advantage of multiplex assay for flow cytometry is ability of measuring a large number of analytes at the same time reducing time of analysis, costs and sample volume [108].

A comprehensive study of the immune signature of MPM may contribute to understanding the immuneevasion mechanisms related to tumor growth, concurring to differential diagnosis and prognostic stratification.

Using multiparametric flow cytometry, Salaroglio et al. [109], analyzed simultaneously immune infiltrate of either pleural fluid and biopsy specimens of pleural tissue from 275 patients with pleural effusion of unknown cause. So, they described an immune signature discriminating MPM from pleuritis and from pleural metastases, identifying higher CD8 T cells and Treg cells within pleural fluid as specific biomarkers of MPM. The immune phenotype of pleural fluid cells had no prognostic significance, whereas expression of programmed death 1 (PD-1), lymphocyte activating 3 (LAG-3), and T cell immunoglobulin and mucin domain 3 (TIM-3) in tumor-infiltrating lymphocytes (TILs), but not in T cells in pleural effusion, correlated with lower OS [109].

\section{Discussion}

MPM is a challenging malignancy to treat as early diagnosis is difficult and effective treatments are lacking. Recently, The Cancer Genome Atlas (TCGA) Research Network conducted a comprehensive integrated 
genomic study of MPM. A novel subtype characterized by extensive loss of heterozygosity, expression of the immune checkpoint regulator V-domain Ig suppressor of $\mathrm{T}$ cell activation (VISTA) and a comprehensive analysis of $B A P 1$ mutations emerged as key findings [12].

Disappointingly, the deeper knowledge of MPM biology has not yet translated into the validation of noninvasive biomarkers that can assist in diagnosis (identifying patients with all subtypes of MPM and predicting its development in asbestos-exposed subjects), definition of prognosis and monitor treatments response. The search for circulating biomarkers has been ongoing from 1990s. As several candidates have been investigated only mesothelin obtained FDA approval, but its poor sensitivity limits the utility as diagnostic marker. OPN is a marker of the duration of asbestos exposure and has a potential prognostic role but lacks specificity for MPM. Other studies have shown promising results for HMGB1 (and its hyperacetylated form) and CD138 but their diagnostic role require further validation. A variety of deregulated miRNAs, as well as different new approaches based on proteomics technology, have been proposed as suitable biomarkers and are currently under investigation. Despite technical challenges, also exosomes provide a novel means of uncovering biomarkers in MPM.

As clearly emerges from this work, and from reviews published elsewhere [110-113], none of single biomarkers has ever reached adequate accuracy as to ensure its use in clinical practice. Since MPM is an extremely heterogeneous tumor, also combination of different markers together could contribute to improve diagnostic accuracy. On the other hand, clinical utility of biomarkers is dependent on how they modify subsequent clinical decisions and influence outcomes. At moment, no evidence suggests that early detection of MPM can improve survival and none of these biomarkers is recommended for screening.

More of biomarkers were studied retrospectively in small cohorts of patients, whereas analytical and preanalytical heterogeneity affect strength of conclusions. Improvement of diagnostic accuracy, standardization of the different assays for reproducibility, choice of appropriate cut-off for each biomarker represent the main critical issues to ensure translation to daily clinical practice. Broad application of a next generation of high-performance technologies based on machine learning algorithms is expected to have a significant impact on the implementation of liquid biopsy [114]. Therefore, integration of multidisciplinary skills and increased international cooperation appears essential for improving validity of results and ensure translation to clinical practice.

\section{Abbreviations}

AES: asbestos exposed subject

BAP1: BRCA1 associated protein

BRD: benign respiratory diseases

CD138: syndecan-1

CDKN2A: cyclin-dependent kinase inhibitor 2A

cfDNA: circulating free DNA

CTCs: circulating tumor cells

ctDNA: circulating tumor DNA

ELISA: enzyme-linked immunosorbent assay

EMT: epithelial mesenchymal transition

EpCAM: expressing epithelial cell adhesion molecule

EV: extracellular vesicles

FBLN3: fibulin-3

FOXK1: Forkhead-box K1

HMGB1: high-mobility group box 1

HS: healty subjects 
miRNAs: microRNAs

MPF: megakaryocyte potentiating factor

MPM: malignant pleural mesothelioma

mRNA: messenger RNA

MS: mass spectrometry

NF2: neurofibromatosis 2

NSCLC: non-small cell lung cancer

OPD: other pleural diseases

OPE: other pleural effusions

OPN: osteopontin

OS: overall survival

PFS: progression free survival

PPV: positive predictive value

SMRP: soluble mesothelin related peptide

SPARC: secreted protein acidic and rich in cysteine

TM: thrombomodulin

VEGF: vascular endothelial growth factor

WEA: workers ex-exposed to asbestos

\section{Declarations}

\section{Author contributions}

GV designed the paper and wrote the manuscript. DDN co-wrote the manuscript. MB and RL reviewed the literature. MF, ADT and GG provided critical revision of the article. All authors read and approved the submitted version.

\section{Conflict of interests}

The authors declare that they have no conflict of interest.

\section{Ethical approval}

Not applicable.

\section{Consent to participate}

Not applicable.

\section{Consent to publication}

Not applicable.

\section{Availability of data and materials}

Not applicable.

\section{Funding}

Not applicable.

\section{Copyright}

(C) The Authors 2020. 


\section{References}

1. Pelucchi C, Malvezzi M, La Vecchia C, Levi F, Decarli A, Negri E. The Mesothelioma epidemic in Western Europe: an update. Br J Cancer. 2004;90:1022-4.

2. Viscardi G, Di Liello R, Morgillo F. How I treat malignant pleural mesothelioma. ESMO Open. 2020;4 Suppl 2:e000669.

3. Hegmans JP, Hemmes A, Hammad H, Boon L, Hoogsteden HC, Lambrecht BN. Mesothelioma environment comprises cytokines and T-regulatory cells that suppress immune responses. Eur Respir J. 2006;27:1086-95.

4. Bueno R, Stawiski EW, Goldstein LD, Durinck S, De Rienzo A, Modrusan Z, et al. Comprehensive genomic analysis of malignant pleural mesothelioma identifies recurrent mutations, gene fusions and splicing alterations. Nat Genet. 2016;48:407-16.

5. Pass HI, Carbone M. Current status of screening for malignant pleural mesothelioma. Semin Thorac Cardiovasc Surg. 2009;21:97-104.

6. Marchevsky AM. Application of immunohistochemistry to the diagnosis of malignant mesothelioma. Arch Pathol Lab Med. 2008;132:397-401.

7. Husain AN, Colby TV, Ordóñez NG, Allen TC, Attanoos RL, Beasley MB, et al. Guidelines for pathologic diagnosis of malignant mesothelioma 2017 update of the consensus statement from the international mesothelioma interest group. Arch Pathol Lab Med. 2018;142:89-108.

8. Berg KB, Churg A. GATA3 immunohistochemistry for distinguishing sarcomatoid and desmoplastic mesothelioma from sarcomatoid carcinoma of the lung. Am J Surg Pathol. 2017;41:1221-5.

9. Hwang HC, Sheffield BS, Rodriguez S, Thompson K, Tse CH, Gown AM, et al. Utility of BAP1 immunohistochemistry and p16 (CDKN2A) FISH in the diagnosis of malignant mesothelioma in effusion cytology specimens. Am J Surg Pathol. 2016;40:120-6.

10. Nasu M, Emi M, Pastorino S, Tanji M, Powers A, Luk H, et al. High incidence of somatic BAP1 alterations in sporadic malignant mesothelioma. J Thorac Oncol. 2015;10:565-76.

11. llei PB, Rusch VW, Zakowski MF, Ladanyi M. Homozygous deletion of CDKN2A and codeletion of the methylthioadenosine phosphorylase gene in the majority of pleural mesotheliomas. Clin Cancer Res. 2003;9:2108-13.

12. Hmeljak J, Sanchez-Vega F, Hoadley KA, Shih J, Stewart C, Heiman D, et al. Integrative molecular characterization of malignant pleural mesothelioma. Cancer Discov. 2018;8:1548-65.

13. Rossi G, Ignatiadis M. Promises and pitfalls of using liquid biopsy for precision medicine. Cancer Res. 2019;79:2798-804.

14. Chang K, Pastan I. Molecular cloning of mesothelin, a differentiation antigen present on mesothelium, mesotheliomas, and ovarian cancers. Proc Natl Acad Sci USA. 1996;93:136-40.

15. Beyer HL, Geschwindt RD, Glover CL, Tran L, Hellstrom I, Hellstrom KE, et al. MESOMARK: a potential test for malignant pleural mesothelioma. Clin Chem. 2007;53:666-72.

16. Robinson BW, Creaney J, Lake R, Nowak A, Musk AW, de Klerk N, et al. Mesothelin-family proteins and diagnosis of mesothelioma. Lancet. 2003;362:1612-6.

17. Hollevoet K, Reitsma JB, Creaney J, Grigoriu BD, Robinson BW, Scherpereel A, et al. Serum mesothelin for diagnosing malignant pleural mesothelioma: an individual patient data meta-analysis. J Clin Oncol. 2012;30:1541-9.

18. Shiomi K, Shiomi S, Ishinaga Y, Sakuraba M, Hagiwara Y, Miyashita K, et al. Impact of renal failure on the tumor markers of mesothelioma, N-ERC/mesothelin and osteopontin. Anticancer Res. 2011;31:1427-30.

19. Tan K, Kajino K, Momose S, Masaoka A, Sasahara K, Shiomi K, et al. Mesothelin (MSLN) promoter is hypomethylated in malignant mesothelioma, but its expression is not associated with methylation status of the promoter. Hum Pathol. 2010;41:1330-8. 
20. Byrne MJ, Nowak AK. Modified RECIST criteria for assessment of response in malignant pleural mesothelioma. Ann Oncol. 2004;15:257-60.

21. Cristaudo A, Foddis R, Vivaldi A, Guglielmi G, Dipalma N, Filiberti R, et al. Clinical significance of serum mesothelin in patients with mesothelioma and lung cancer. Clin Cancer Res. 2007;13:5076-81.

22. Grigoriu BD, Scherpereel A, Devos P, Chahine B, Letourneux M, Lebailly P, et al. Utility of osteopontin and serum mesothelin in malignant pleural mesothelioma diagnosis and prognosis assessment. Clin Cancer Res. 2007;13:2928-35.

23. Schneider J, Hoffmann H, Dienemann H, Herth FJ, Meister M, Muley T, et al. Diagnostic and prognostic value of soluble mesothelin-related proteins in patients with malignant pleural mesothelioma in comparison with benign asbestosis and lung cancer. J Thorac Oncol. 2008;3:1317-24.

24. Creaney J, Francis RJ, Dick IM, Musk AW, Robinson BW, Byrne MJ, et al. Serum soluble mesothelin concentrations in malignant pleural mesothelioma: relationship to tumor volume, clinical stage and changes in tumor burden. Clin Cancer Res. 2011;17:1181-9.

25. Wheatley-Price P, Yang B, Patsios D, Patel D, Ma C, Xu W, et al. Soluble mesothelin-related peptide and osteopontin as markers of response in malignant mesothelioma. J Clin Oncol. 2010;28:3316-22.

26. Lv J, Li P. Mesothelin as a biomarker for targeted therapy. Biomark Res. 2019;7:18.

27. Onda M, Nagata S, Ho M, Bera TK, Hassan R, Alexander RH, et al. Megakaryocyte potentiation factor cleaved from mesothelin precursor is a useful tumor marker in the serum of patients with mesothelioma. Clin Cancer Res. 2006;12:4225-31.

28. Hassan R, Sharon E, Thomas A, Zhang J, Ling A, Miettinen M, et al. Phase 1 study of the antimesothelin immunotoxin SS1P in combination with pemetrexed and cisplatin for front-line therapy of pleural mesothelioma and correlation of tumor response with serum mesothelin, megakaryocyte potentiating factor, and cancer antigen 125. Cancer. 2014;120:3311-9.

29. Hassan R, Miller AC, Sharon E, Thomas A, Reynolds JC, Ling A, et al. Major cancer regressions in mesothelioma after treatment with an anti-mesothelin immunotoxin and immune suppression. Sci Transl Med. 2013;5:208ra147.

30. Cao L, Yu Y, Thomas A, Zhang J, Onda M, Meltzer P, et al. Megakaryocyte potentiating factor as a predictive biomarker for therapies against malignant mesothelioma. JCO Precis Oncol. 2018;2018:PO.17.00282.

31. Furger KA, Menon RK, Tuck AB, Bramwell VH, Chambers AF. The functional and clinical roles of osteopontin in cancer and metastasis. Curr Mol Med. 2001;1:621-32.

32. Castello LM, Raineri D, Salmi L, Clemente N, Vaschetto R, Quaglia M, et al. Osteopontin at the crossroads of inflammation and tumor progression. Mediators Inflamm. 2017;2017:4049098.

33. Rittling SR, Chambers AF. Role of osteopontin in tumour progression. Br J Cancer. 2004;90:1877-81.

34. Pass HI, Lott D, Lonardo F, Harbut M, Liu Z, Tang N, et al. Asbestos exposure, pleural mesothelioma, and serum osteopontin levels. N Engl J Med. 2005;353:1564-73.

35. Hu ZD, Liu XF, Liu XC, Ding CM, Hu CJ. Diagnostic accuracy of osteopontin for malignant pleural mesothelioma: a systematic review and meta-analysis. Clin Chim Acta. 2014;433:44-8.

36. Cristaudo A, Foddis R, Bonotti A, Simonini S, Vivaldi A, Guglielmi G, et al. Comparison between plasma and serum osteopontin levels: usefulness in diagnosis of epithelial malignant pleural mesothelioma. Int J Biol Markers. 2010;25:164-70.

37. Vordermark D, Said HM, Katzer A, Kuhnt T, Hänsgen G, Dunst J, et al. Plasma osteopontin levels in patients with head and neck cancer and cervix cancer are critically dependent on the choice of ELISA system. BMC Cancer. 2006;6:207.

38. Hollevoet K, Nackaerts K, Gosselin R, De Wever W, Bosquée L, De Vuyst P, et al. Soluble mesothelin, megakaryocyte potentiating factor, and osteopontin as markers of patient response and outcome in mesothelioma. J Thorac Oncol. 2011;6:1930-7. 
39. Cristaudo A, Bonotti A, Simonini S, Vivaldi A, Guglielmi G, Ambrosino N, et al. Combined serum mesothelin and plasma osteopontin measurements in malignant pleural mesothelioma. J Thorac Oncol. 2011;6:1587-93.

40. Kobayashi N, Kostka G, Garbe JH, Keene DR, Bächinger HP, Hanisch FG, et al. A comparative analysis of the fibulin protein family. Biochemical characterization, binding interactions, and tissue localization. J Biol Chem. 2007;282:11805-6.

41. Gallagher WM, Currid CA, Whelan LC. Fibulins and cancer: friend or foe? Trends Mol Med. 2005;11:336-40.

42. Pass HI, Levin SM, Harbut MR, Melamed J, Chiriboga L, Donington J, et al. Fibulin-3 as a blood and effusion biomarker for pleural mesothelioma. N Engl J Med. 2012;367:1417-27.

43. Creaney J, Dick IM, Meniawy TM, Leong SL, Leon JS, Demelker Y, et al. Comparison of fibulin-3 and mesothelin as markers in malignant mesothelioma. Thorax. 2014;69:895-902.

44. Kirschner MB, Pulford E, Hoda MA, Rozsas A, Griggs K, Cheng YY, et al. Fibulin-3 levels in malignant pleural mesothelioma are associated with prognosis but not diagnosis. Br J Cancer. 2015;113:963-9.

45. Yanai H, Ban T, Wang Z, Choi MK, Kawamura T, Negishi H, et al. HMGB proteins function as universal sentinels for nucleic-acid-mediated innate immune responses. Nature. 2009;462:99-103.

46. Yang H, Rivera Z, Jube S, Nasu M, Bertino P, Goparaju C, et al. Programmed necrosis induced by asbestos in human mesothelial cells causes high-mobility group box 1 protein release and resultant inflammation. Proc Natl Acad Sci U S A. 2010;107:12611-6.

47. Tabata C, Shibata E, Tabata R, Kanemura S, Mikami K, Nogi Y, et al. Serum HMGB1 as a prognostic marker for malignant pleural mesothelioma. BMC Cancer. 2013;13:205.

48. Napolitano A, Antoine DJ, Pellegrini L, Baumann F, Pagano I, Pastorino S, et al. HMGB1 and its hyperacetylated isoform are sensitive and specific serum biomarkers to detect asbestos exposure and to identify mesothelioma patients. Clin Cancer Res. 2016;22:3087-96.

49. Strizzi L, Catalano A, Vianale G, Orecchia S, Casalini A, Tassi G, et al. Vascular endothelial growth factor is an autocrine growth factor in human malignant mesothelioma. J Pathol. 2001;193:468-75.

50. Ohta Y, Shridhar V, Bright RK, Kalemkerian GP, Du W, Carbone M, et al. VEGF and VEGF type C play an important role in angiogenesis and lymphangiogenesis in human malignant mesothelioma tumours. $\mathrm{Br}$ J Cancer. 1999;81:54-61.

51. Lee JK, Hong YJ, Han CJ, Hwang DY, Hong SI. Clinical usefulness of serum and plasma vascular endothelial growth factor in cancer patients: which is the optimal specimen? Int J Oncol. 2000;17:149-52.

52. Hirayama N, Tabata C, Tabata R, Maeda R, Yasumitsu A, Yamada S, et al. Pleural effusion VEGF levels as a prognostic factor of malignant pleural mesothelioma. Respir Med. 2011;105:137-42.

53. Yasumitsu A, Tabata C, Tabata R, Hirayama N, Murakami A, Yamada S, et al. Clinical significance of serum vascular endothelial growth factor in malignant pleural mesothelioma. J Thorac Oncol. 2010;5:479-83.

54. Fiorelli A, Vicidomini G, Di Domenico M, Napolitano F, Messina G, Morgillo F, et al. Vascular endothelial growth factor in pleural fluid for differential diagnosis of benign and malignant origin and its clinical applications. Interact Cardiovasc Thorac Surg. 2011;12:420-4.

55. Nowak AK, Brosseau S, Cook A, Zalcman G. Antiangiogeneic strategies in mesothelioma. Front Oncol. 2020;10:126.

56. Zalcman G, Mazieres J, Margery J, Greillier L, Audigier-Valette C, Moro-Sibilot D, et al. Bevacizumab for newly diagnosed pleural mesothelioma in the mesothelioma avastin cisplatin pemetrexed study (MAPS): a randomised, controlled, open-label, phase 3 trial. Lancet. 2016;387:1405-14.

57. Grosso F, Steele N, Novello S, Nowak AK, Popat S, Greillier L, et al. Nintedanib plus pemetrexed/cisplatin in patients with malignant pleural mesothelioma: phase II results from the randomized, placebocontrolled LUME-Meso trial. J Clin Oncol. 2017;35:3591-600.

58. Carey DJ. Syndecans: multifunctional cell-surface co-receptors. Biochem J. 1997;327:1-16. 
59. Mundt F, Heidari-Hamedani G, Nilsonne G, Metintas M, Hjerpe A, Dobra K. Diagnostic and prognostic value of soluble syndecan-1 in pleural malignancies. Biomed Res Int. 2014;2014:419853.

60. Borrebaeck CA. Precision diagnostics: moving towards protein biomarker signatures of clinical utility in cancer. Nat Rev Cancer. 2017;17:199-204.

61. Aebersold R, Mann M. Mass spectrometry-based proteomics. Nature. 2003;422:198-207.

62. Cerciello F, Choi M, Nicastri A, Bausch-Fluck D, Ziegler A, Vitek O, et al. Identification of a seven glycopeptide signature for malignant pleural mesothelioma in human serum by selected reaction monitoring. Clin Proteomics. 2013;10:16.

63. Kao SC, Kirschner MB, Cooper WA, Tran T, Burgers S, Wright C, et al. A proteomics-based approach identifies secreted protein acidic and rich in cysteine as a prognostic biomarker in malignant pleural mesothelioma. Br J Cancer. 2016;114:524-31.

64. Song X, Bandow J, Sherman J, Baker JD, Brown PW, McDowell MT, et al. iTRAQ experimental design for plasma biomarker discovery. J Proteome Res. 2008;7:2952-8.

65. Tai IT, Tang MJ. SPARC in cancer biology: its role in cancer progression and potential for therapy. Drug Resist Updat. 2008;11:231-46.

66. Ostroff RM, Mehan MR, Stewart A, Ayers D, Brody EN, Williams SA, et al. Early detection of malignant pleural mesothelioma in asbestos-exposed individuals with a noninvasive proteomics-based surveillance tool. PLoS One. 2012;7:e46091.

67. Gold L, Ayers D, Bertino J, Bock C, Bock A, Brody EN, et al. Aptamer-based multiplexed proteomic technology for biomarker discovery. PLoS One. 2010;5:e15004.

68. Kraemer S, Vaught JD, Bock C, Gold L, Katilius E, Keeney TR, et al. From SOMAmer-based biomarker discovery to diagnostic and clinical applications: a SOMAmer-based, streamlined multiplex proteomic assay. PLoS One. 2011;6:e26332.

69. O'Brien J, Hayder H, Zayed Y, Peng C. Overview of microRNA biogenesis, mechanisms of actions, and circulation. Front Endocrinol (Lausanne). 2018;9:402.

70. Peng Y, Croce CM. The role of microRNAs in human cancer. Signal Transduct Target Ther. 2016;1:15004.

71. Cortez MA, Calin GA. MicroRNA identification in plasma and serum: a new tool to diagnose and monitor diseases. Expert Opin Biol Ther. 2009;9:703-11.

72. Git A, Dvinge H, Salmon-Divon M, Osborne M, Kutter C, Hadfield J, et al. Systematic comparison of microarray profiling, real-time PCR, and next-generation sequencing technologies for measuring differential microRNA expression. RNA. 2010;16:991-1006.

73. Faraldi M, Gomarasca M, Sansoni V, Perego S, Banfi G, Lombardi G. Normalization strategies differently affect circulating miRNA profile associated with the training status. Sci Rep. 2019;9:1584.

74. Lo Russo G, Tessari A, Capece M, Galli G, de Braud F, Garassino MC, et al. MicroRNAs for the diagnosis and management of malignant pleural mesothelioma: a literature review. Front Oncol. 2018;8:650.

75. Guled M, Lahti L, Lindholm PM, Salmenkivi K, Bagwan I, Nicholson AG, et al. CDKN2A, NF2, and JUN are dysregulated among other genes by miRNAs in malignant mesothelioma-a miRNA microarray analysis. Genes Chromosomes Cancer. 2009;48:615-23.

76. Taniguchi T, Karnan S, Fukui T, Yokoyama T, Tagawa H, Yokoi K, et al. Genomic profiling of malignant pleural mesothelioma with array-based comparative genomic hybridization shows frequent non-random chromosomal alteration regions including JUN amplification on 1p32. Cancer Sci. 2007;98:438-46.

77. Santarelli L, Strafella E, Staffolani S, Amati M, Emanuelli M, Sartini D, et al. Association of MiR-126 with soluble mesothelin-related peptides, a marker for malignant mesothelioma. PLoS One. 2011;6:e18232.

78. Santarelli L, Staffolani S, Strafella E, Nocchi L, Manzella N, Grossi P, et al. Combined circulating epigenetic markers to improve mesothelin performance in the diagnosis of malignant mesothelioma. Lung Cancer. 2015;90:457-64. 
79. Tomasetti M, Staffolani S, Nocchi L, Neuzil J, Strafella E, Manzella N, et al. Clinical significance of circulating miR-126 quantification in malignant mesothelioma patients. Clin Biochem. 2012;45:575-81.

80. Benz F, Roderburg C, Vargas Cardenas D, Vucur M, Gautheron J, Koch A, et al. U6 is unsuitable for normalization of serum miRNA levels in patients with sepsis or liver fibrosis. Exp Mol Med. 2013;45:e42.

81. Weber DG, Gawrych K, Casjens S, Brik A, Lehnert M, Taeger D, et al. Circulating miR-132-3p as a candidate diagnostic biomarker for malignant mesothelioma. Dis Markers. 2017;2017:9280170.

82. Bononi I, Comar M, Puozzo A, Stendardo M, Boschetto P, Orecchia S, et al. Circulating microRNAs found dysregulated in ex-exposed asbestos workers and pleural mesothelioma patients as potential new biomarkers. Oncotarget. 2016;7:82700-11.

83. Wu W, Yang J, Feng X, Wang H, Ye S, Yang P, et al. MicroRNA-32 (miR-32) regulates phosphatase and tensin homologue (PTEN) expression and promotes growth, migration, and invasion in colorectal carcinoma cells. Mol Cancer. 2013;12:30.

84. Kirschner MB, Cheng YY, Badrian B, Kao SC, Creaney J, Edelman JJ, et al. Increased circulating miR625-3p: a potential biomarker for patients with malignant pleural mesothelioma. J Thorac Oncol. 2012;7:1184-91.

85. Kirschner MB, Edelman JJ, Kao SC, Vallely MP, van Zandwijk N, Reid G. The impact of hemolysis on cellfree microRNA biomarkers. Front Genet. 2013;4:94.

86. Fang L, Kong D, Xu W. MicroRNA-625-3p promotes the proliferation, migration and invasion of thyroid cancer cells by up-regulating astrocyte elevated gene 1. Biomed Pharmacother. 2018;102:203-11.

87. Cavalleri T, Angelici L, Favero C, Dioni L, Mensi C, Bareggi C, et al. Plasmatic extracellular vesicle microRNAs in malignant pleural mesothelioma and asbestos-exposed subjects suggest a 2-miRNA signature as potential biomarker of disease. PLoS One. 2017;12:e176680.

88. Weber DG, Johnen G, Bryk O, Jöckel KH, Brüning T. Identification of miRNA-103 in the cellular fraction of human peripheral blood as a potential biomarker for malignant mesothelioma--a pilot study. PLoS One. 2012;7:e30221.

89. Weber DG, Casjens S, Johnen G, Bryk O, Raiko I, Pesch B, et al. Combination of MiR-103a-3p and mesothelin improves the biomarker performance of malignant mesothelioma diagnosis. PLoS One. 2014;9:e114483.

90. Wan JCM, Massie C, Garcia-Corbacho J, Mouliere F, Brenton JD, Caldas C, et al. Liquid biopsies come of age: towards implementation of circulating tumour DNA. Nat Rev Cancer. 2017;17:223-38.

91. Sriram KB, Relan V, Clarke BE, Duhig EE, Windsor MN, Matar KS, et al. Pleural fluid cell-free DNA integrity index to identify cytologically negative malignant pleural effusions including mesotheliomas. BMC Cancer. 2012;12:428.

92. Hylebos M, Op de Beeck K, Pauwels P, Zwaenepoel K, van Meerbeeck JP, Van Camp G. Tumor-specific genetic variants can be detected in circulating cell-free DNA of malignant pleural mesothelioma patients. Lung Cancer. 2018;124:19-22.

93. Yap TA, Lorente D, Omlin A, Olmos D, de Bono JS. Circulating tumor cells: a multifunctional biomarker. Clin Cancer Res. 2014;20:2553-68.

94. Rao CG, Chianese D, Doyle GV, Miller MC, Russell T, Sanders RA Jr, et al. Expression of epithelial cell adhesion molecule in carcinoma cells present in blood and primary and metastatic tumors. Int J Oncol. 2005;27:49-57.

95. Wang L, Balasubramanian P, Chen AP, Kummar S, Evrard YA, Kinders RJ. Promise and limits of the CellSearch platform for evaluating pharmacodynamics in circulating tumor cells. Semin Oncol. 2016;43:464-75.

96. Kimura N, Kimura I. Podoplanin as a marker for mesothelioma. Pathol Int. 2005;55:83-6.

97. Yoneda K, Kuwata T, Chikaishi Y, Mori M, Kanayama M, Takenaka M, et al. Detection of circulating tumor cells with a novel microfluidic system in malignant pleural mesothelioma. Cancer Sci. 2019;110:726-33. 
98. Sharma S, Kelly TK, Jones PA. Epigenetics in cancer. Carcinogenesis. 2010;31:27-36.

99. Christensen BC, Godleski JJ, Marsit CJ, Houseman EA, Lopez-Fagundo CY, Longacker JL, et al. Asbestos exposure predicts cell cycle control gene promoter methylation in pleural mesothelioma. Carcinogenesis. 2008;29:1555-9.

100. Nocchi L, Tomasetti M, Amati M, Neuzil J, Santarelli L, Saccucci F. Thrombomodulin is silenced in malignant mesothelioma by apoly(ADP-ribose) polymerase-1-mediated epigenetic mechanism. J Biol Chem. 2011;286:19478-88.

101. Andersen M, Trapani D, Ravn J, Sørensen JB, Andersen CB, Grauslund M, et al. Methylation-associated silencing of microRNA-126 and its host gene EGFL7 in malignant pleural mesothelioma. Anticancer Res. 2015;35:6223-9.

102. Guarrera S, Viberti C, Cugliari G, Allione A, Casalone E, Betti M, et al. Peripheral blood DNA methylation as potential biomarker of malignant pleural mesothelioma in asbestos-exposed subjects. J Thorac Oncol. 2019;14:527-39.

103. Huang JT, Lee V. Identification and characterization of a novel human FOXK1 gene in silico. Int J Oncol. 2004;25:751-7.

104. Testa JR, Cheung M, Pei J, Below JE, Tan Y, Sementino E, et al. Germline BAP1 mutations predispose to malignant mesothelioma. Nat Genet. 2011;43:1022-5.

105. Ahmadzada T, Kao S, Reid G, Clarke S, Grau GE, Hosseini-Beheshti E. Extracellular vesicles as biomarkers in malignant pleural mesothelioma: a review. Crit Rev Oncol Hematol. 2020;150:102949.

106. Creaney J, Dick IM, Leon JS, Robinson BW. A proteomic analysis of the malignant mesothelioma secretome using iTRAQ. Cancer Genomics Proteomics. 2017;14:103-17.

107. Bard MP, Hegmans JP, Hemmes A, Luider TM, Willemsen R, Severijnen LA, et al. Proteomic analysis of exosomes isolated from human malignant pleural effusions. Am J Respir Cell Mol Biol. 2004;31:114-21.

108. Antal-Szalmás P, Nagy B Jr, Debreceni IB, Kappelmayer J. Measurement of soluble biomarkers by flow cytometry. EJIFCC. 2013;23:135-42.

109. Salaroglio IC, Kopecka J, Napoli F, Pradotto M, Maletta F, Costardi L, et al. Potential diagnostic and prognostic role of microenvironment in malignant pleural mesothelioma. J Thorac Oncol. 2019;14:1458-71.

110. Arnold DT, De Fonseka D, Hamilton FW, Rahman NM, Maskell NA. Prognostication and monitoring of mesothelioma using biomarkers: a systematic review. Br J Cancer. 2017;116:731-41.

111. Creaney J, Robinson BWS. Malignant mesothelioma biomarkers: from discovery to use in clinical practice for diagnosis, monitoring, screening, and treatment. Chest. 2017;152:143-9.

112. Cristaudo A, Bonotti A, Guglielmi G, Fallahi P, Foddis R. Serum mesothelin and other biomarkers: what have we learned in the last decade? J Thorac Dis. 2018;10 Suppl 2:S353-9.

113. Cavallari I, Urso L, Sharova E, Pasello G, Ciminale V. Liquid biopsy in malignant pleural mesothelioma: state of the art, pitfalls, and perspectives. Front Oncol. 2019;9:740.

114. Azuaje F. Artificial intelligence for precision oncology: beyond patient stratification. NPJ Precis Oncol. 2019;3:6. 